\title{
Review: thrombolytic treatment does not reduce the risk of recurrent pulmonary embolism and death more than heparin
}

Wan S, Quinlan DJ, Agnelli G, et al. Thrombolysis compared with heparin for the initial treatment of pulmonary embolism: a metaanalysis of the randomized controlled trials. Circulation 2004;110:744-9.

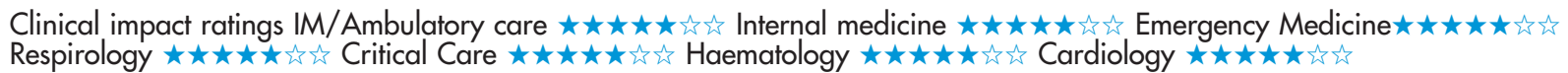

In patients with acute pulmonary embolism (PE), is initial treatment with thrombolysis more effective than heparin for reducing risk of recurrent $P E$ and death?

\section{METHODS}

Data sources: Medline and EMBASE/Excerpta Medica (January
1980 to January 2003), Cochrane Library (2003, Issue 1), and
hand searches of reference lists of retrieved articles and abstracts
of conference proceedings.
Study selection and assessment: published and unpublished
randomised controlled trials (RCTs) that were properly
randomised, compared thrombolysis with heparin for initial
treatment of patients with objectively diagnosed symptomatic PE,
and used objective methods to assess clinical outcomes. 2
independent reviewers assessed methodological quality
(allocation sequence and concealment, blinding, and follow up).
Outcomes: a composite of recurrent PE or death. Secondary
outcomes were PE, death, major bleeding, non-major bleeding,
and intracranial haemorrhage.

\section{MAIN RESULTS}

11 trials $(n=748)$ met the selection criteria. 3 RCTs used random number tables or programs for generating randomised allocation sequences, 5 RCTs provided information on concealment, 3 RCTs had blinding of patients and investigators, and no trial reported loss to follow up. All studies included patients with symptomatic PE, and 5 trials included patients with major PE (haemodynamic instability). Thrombolysis included urokinase, streptokinase, and tissue plasminogen activator. Meta-analysis (fixed effects model) of 11 trials showed that thrombolysis and heparin did not differ for the composite endpoint, recurrent PE, or death (table). Groups did not differ for major bleeding ( 11 trials) and intracranial haemorrhage (11 trials) (table). However, more patients who received thrombolysis had non-major bleeding than those who received heparin (table).

For correspondence: Dr J W Eikelboom, Depatment of Haematology, Royal Perth Hospital, Perth, West Australia, Australia. John.eikelboom@health.wa. gov.au

Source of funding: no external funding.

\section{CONCLUSIONS}

In unselected patients with acute pulmonary embolism (PE), thrombolysis does not reduce the risk of recurrent PE and death more than heparin. Thrombolysis increases the risk of non-major bleeding.

\section{Commentary}

ThE he exact role of thrombolytic treatment in the management of acute $\mathrm{PE}$ remains controversial. Uncertainty over the balance between risk and benefit fuels this controversy. Thrombolytic agents accelerate the dissolution of venous thrombi, but they also increase the risk of serious bleeding. The authors of the 7 th consensus statement of the American College of Chest Physicians recommend that clinicians not use systemic thrombolytic treatment for most patients with acute PE. 'The meta-analysis by Wan et al supports this position.

The principal result of the review is no surprise since 6 of 11 trials in the meta-analysis excluded patients who were haemodynamically unstable. A more telling observation lies in the subgroup analysis of 5 trials that did include haemodynamically unstable patients. This analysis suggests that thrombolysis reduces the likelihood of the composite outcome of recurrent PE or death. It does not show a survival benefit (odds ratio $0.47,95 \% \mathrm{Cl}$ 0.20 to 1.10 ). However, the number of patients who were randomised was small $(n=254)$, and even fewer patients were haemodynamically unstable. Thus, the review by Wan et al has limited power to detect a survival benefit.

The meta-analysis also underscores the importance of risk stratification for patients with acute PE. However, important questions remain. For example, how should we identify patients at high risk? We know that normotensive patients with right ventricular hypokinesis on echocardiography have increased mortality, but we do not know whether thrombolysis reduces their mortality. Further meta-analyses of existing data are unlikely to be helpful. A large clinical trial that enrols high risk patients with acute PE is needed to address the persistent controversy over the exact role of thrombolysis for these patients.

Greg Elliott, MD Scott Stevens, MD LDS Hospital and the University of Utah Salt Lake City, Utah, USA

1 Büller HR, Agnelli G, Hull RD, et al. Antithrombotic therapy for venous thromboembolic disease: the Seventh ACCP Conference on Antithrombotic and Thrombolytic Therapy. Chest 2004;126:401S-28S.

Thrombolysis $v$ heparin for recurrent pulmonary embolism $(\mathrm{PE})^{*}$

\begin{tabular}{lcccl}
\hline $\begin{array}{l}\text { Outcomes during hospital } \\
\text { stay or to } 30 \text { days }\end{array}$ & Thrombolysis & Heparin & RRR (95\% CI) & NNT (CI) \\
\hline Recurrent PE or death & $6.7 \%$ & $9.6 \%$ & $31 \%(-11$ to 56$)$ & Not significant \\
$\begin{array}{l}\text { Recurrent PE } \\
\text { Death }\end{array}$ & $2.7 \%$ & $4.3 \%$ & $32 \%(-35$ to 66$)$ & Not significant \\
& $4.3 \%$ & $5.9 \%$ & $29 \%(-28$ to 62$)$ & Not significant \\
\hline & & & RRI (CI) & NNH (CI) \\
\hline $\begin{array}{l}\text { Major bleeding } \\
\text { Non-major bleeding }\end{array}$ & $9.1 \%$ & $6.1 \%$ & $38 \%(-18$ to 126$)$ & Not significant \\
Intracranial haemorrhage & $23 \%$ & $10 \%$ & $140 \%(48$ to 276$)$ & $13(7$ to 36$)$ \\
\hline
\end{tabular}

*Abbreviations defined in glossary; RRR, RRI, NNT, NNH, and Cl calculated from control event rate and odds ratio in article. 